\title{
Probing the sedimentary DOM in the deepest sector of Earth's surface
}

\author{
TINGCANG HU ${ }^{1}$, MIN LUO ${ }^{2}$, URBAN J. WÜNSCH ${ }^{3}$, \\ YUNPING XU ${ }^{1}$, JIASONG FANG ${ }^{1}$ AND DUOFU CHEN $^{1}$ \\ ${ }^{1}$ Shanghai Ocean University \\ ${ }^{2}$ Shanghai Ocean Univerisity \\ ${ }^{3}$ Technical University of Denmark \\ Presenting Author: mluo@shou.edu.cn
}

It has been suggested that hadal trenches are depocenters of organic matter and hotspots for microbial activities. Here, we report the concentrations of pore-water dissolved organic carbon (DOC) in the sediment cores retrieved from the Mariana Trench, the Mussau Trench, and the New Britain Trench, and present the optical properties of pore-water dissolved organic matter (DOM) at the Mariana Trench. The positive correlation between the average DOC concentrations and the in-situ total oxygen uptakes among the three trenches suggests that rate of organic matter mineralization and redox condition likely control the downcore pore-water DOC concentrations in hadal sediments. Furthermore, analysis of fluorescence DOM reveals a higher carbonnormalized fluorescence of components emitting in the visible ("humic" and "fulvic"-like) at the Mariana Trench axis than at the abyssal plain and overriding plate. Together with the downcore increase in humification indices and absorbance ratios at the trench axis cores, this points at a significant accumulation of highly degraded, persistent, low-molecular-weight DOM produced by intensified microbial respiration at the trench axis. To our knowledge, this is the first study that examines the features of pore-water DOM in hadal trenches, which provides additional supports for the argument that microbial activities are enhanced at the trench axis and has implication for understanding DOM cycling in deep-sea sediments 